\title{
6-STROKE ENGINE: THERMODYNAMIC MODELLING AND DESIGN FOR TESTING
}

\author{
Atip Nimsiriwangso, Paul Barnes, Omid Doustdar, Miroslaw L. Wyszynski \\ University of Birmingham, Department of Mechanical Engineering \\ Birmingham B15 2TT, UK \\ tel.: +44 121 4144159, e-mail:m.l.wyszynski@bham.ac.uk
}

Gasim Mohamed Maisara Mohyeldin

Prince Sattam bin Abdulaziz University (Saudi Arabia)

Project 2017/01/6994

Miroslaw Kowalski

Air Force Institute of Technology. Ksiecia Boleslawa 6, 01-494 Warsaw, Poland tel.:+4822851301,fax: +4822851313e-mail: miroslaw.kowalski@itwl.pl

\begin{abstract}
In the study AVL BOOST TM is used to perform a thermodynamic simulation of a six-stroke engine, being built by a research team based in Saudi Arabia. The six-stroke cycle consists of a standard four-stroke Otto Cycle followed by a heat recovering steam expansion cycle. Water is injected into the hot combustion chamber towards the end of the Otto expansion stroke producing steam, which is used to perform work on a piston. This process produces power using waste heat and therefore increases the overall efficiency of the engine. The Robin EY28D engine, which is a single cylinder, four-stroke, gasoline engine was used for this simulation study. The engine was modelled and converted into six-stroke engine in AVL BOOST. The results show that six-stroke engine is more efficient than four-stroke engine. In six-stroke engine, the engine power is increased by $33.1 \%$ and brake specific fuel consumption (BSFC) is decreased by approximately 16\%. Where emissions are concerned, Nitrogen Oxide (NOx) emission from six-stroke engine is reduced by 80\%, while the Hydrocarbon (HC) emission increases by $85 \%$ compared with the original 4-stroke. Moreover, the most efficient camshaft was found and designed according to the most efficient valve profile for this engine, which is combination of $60 \mathrm{CA}^{\circ}$ of valve duration and $10 \mathrm{~mm}$ of valve lifting.
\end{abstract}

Keywords: six-stroke engine, water injection, steam expansion, engine efficiency, dynamic gas model

\section{Introduction}

Nowadays, the amount of crude oil consumption is increased every year, while there is less amount of crude oil left in the world. In 2018, the daily global demand for crude oil was up to 99.2 million barrels per day, which means an increase from 2010 by 12.8 million barrel [20]. In fact, up to $44 \%$ of the crude oil is used as gasoline for car fuel and $19 \%$ is used as heating oil and diesel fuel [5]. Therefore, to reduce the consumption of world crude oil, one way is to increase engine efficiency in spark ignition engine, since this engine uses gasoline as a fuel.

In a gasoline engine, approximately $40 \%$ of heat loss is in exhaust, while there is only approximately $25 \%$ remaining as useful energy output [14]. The engine efficiency can be increased by reducing the heat loss via exhaust gas and turning it into a useful energy.

Over the past years, much engineering research has been for the engine with higher engine efficiency and lower fuel consumption. One of the achievements is a six-stroke engine with water injection.

Six-stroke engine is a type of internal combustion engine based on four-stroke engine [14]. However, the waste heat from exhaust stroke in four-stroke is captured and used to perform additional 2 strokes. Working fluid (air or water) is injected into the cylinder towards the end of 
exhaust stroke of the four-stroke engine. As a result, during the fifth stroke the pressure in the cylinder is increased and forces the piston back down to perform second power stroke. The vapour then leaves the cylinder during the sixth stroke [7]. The whole cycle is best illustrated in Fig. 1 [4].

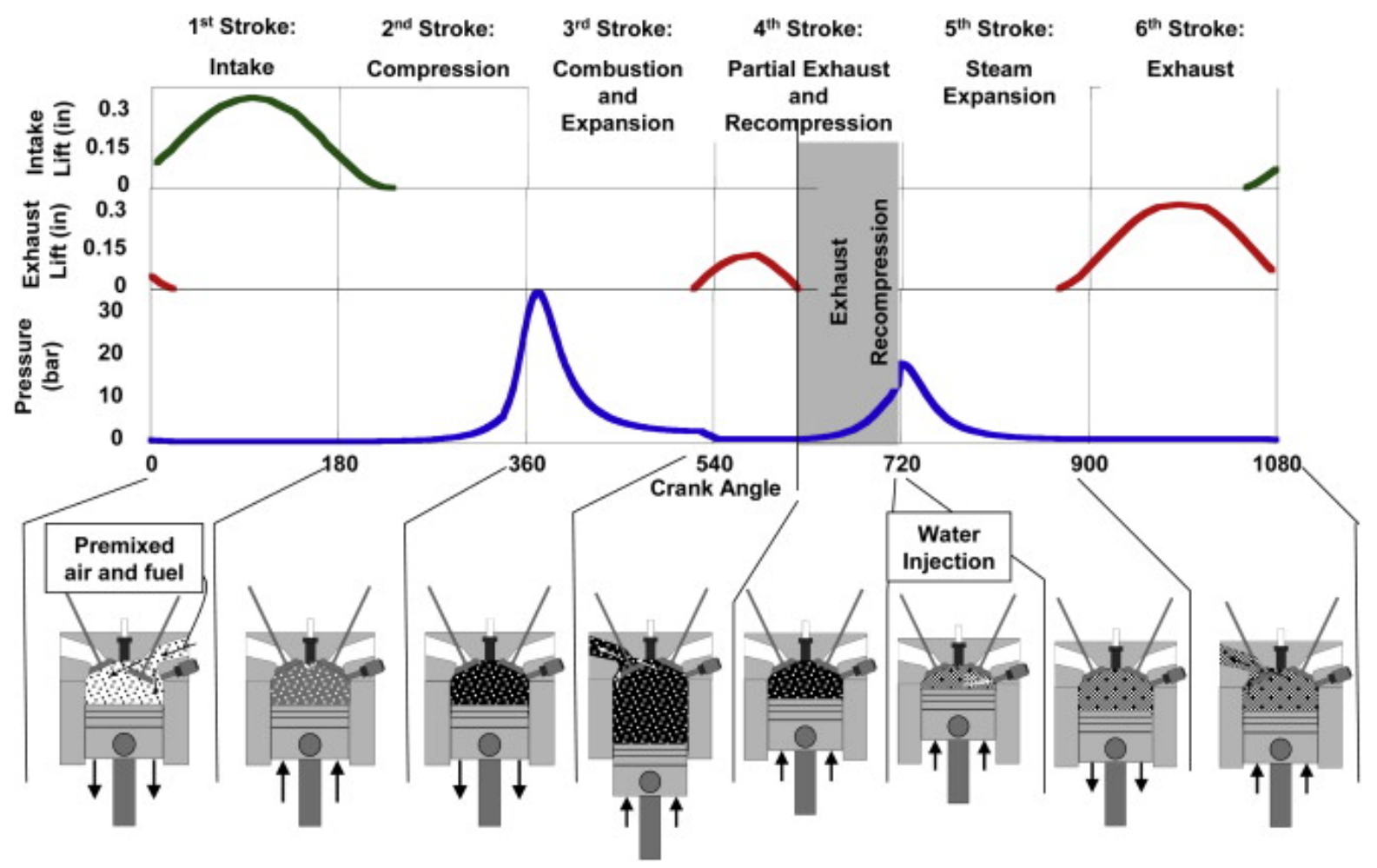

Fig. 1. The six-stroke engine cycle [4]

The exhaust heat loss is converted into useful energy. As a result, more power is produced per cycle. Therefore, the engine efficiency increases, which mean that for the same amount of power, six-stroke engine need less fuel. It can be said that six-stroke engine consumes less fuel that four-stroke engine.

The aims of this study are to investigate on the most efficient camshaft for the Subaru Robin EY28D adapted as a six-stroke engine and engine performance according to the new camshaft.

\section{Literature}

\subsection{Griffin's six-stroke engine}

The first six-stroke engine was developed by Samuel Griffin in 1883. In the Griffin six-stroke engine, two extra strokes were added to a four-stroke engine. In fact, steam was used to perform the extra two strokes. The Griffin engine was be able to produce high amount of power, but its large construction envelope was not suitable to be used in automobile. However, the principle of Griffin engine could be used as a guideline for later six-stroke engine [8].

\subsection{Dyer's six-stroke engine}

Dyer's six-stroke engine is the first six-stroke internal combustion with direct water injection engine. It was invented by Leonard H. Dyer in 1915. In the Dyer's six-stroke engine, water is directly injected into the cylinder after fourth stroke and is quickly evaporated into superheated steam. When water evaporates, the pressure greatly increases in the limited volume and forces the piston down for an additional stroke. Dyer's six-stroke engine showed that the combustion chamber 
is cooled by directly injecting water into the chamber after exhaust gas expanded and was partly expelled from the cylinder. Moreover, Dyer claimed that the exhaust system in six-stroke engine was improved and engine efficiency was increased, due to use of the waste exhaust heat [6].

\subsection{Theoretical study on high efficiency six-stroke engine}

In 2010, a theoretical study of high efficiency six-stroke engine was carried by Szybist and Conklin. In their study, a concept of converting the waste heat from exhaust gas and engine coolant into useful energy was considered. The investigation of this concept was carried by using an ideal thermodynamics model of the exhaust gas compression, water injection, and expansion. A calculation was performed by changing injected mass and exhaust valve closing duration, so that the best amount of exhaust gas could be recompressed resulting in a maximum mean effective pressure of the second power stroke. The result from their calculations showed that in-cylinder pressure increased with the increase of injected mass. In contrast, in-cylinder temperature decreased with the increase of injected mass. Meanwhile, when the exhaust valve closing duration increased, both the in-cylinder temperature and pressure decreased. Moreover, they claimed that their concept has the potential of increase in fuel efficiency without decreasing the power [4].

\subsection{Effect of direct water injection parameters on engine performance}

Arabaci et al. carried out experiment on an actual one-cylinder car engine (Honda GX 270) to investigate the effect of water injection mass and injection duration on engine performance and exhaust emission in a six-stroke engine. The four-stroke gasoline engine was converted to six-stroke. The experiment was performed with different injection parameters. The test result showed that specific fuel consumption and exhaust gas temperature decreased by about $9 \%$ and $7 \%$, respectively. Power output increased by $10 \%$ with water injection. Moreover, $\mathrm{HC}$ and $\mathrm{CO}$ emission decreased by $18.23 \%$ and $21.97 \%$ until $3000 \mathrm{rpm}$ respectively [2].

\subsection{AVL BOOST Model}

Paul Barnes, a BEng student at University of Birmingham, attempted to model a single cylinder, six-stroke engine using the AVL BOOST ${ }^{\mathrm{TM}}$ platform. Unfortunately, the full engine specification was not available to him. Thus, the model was built with some real engine specification and some general single cylinder engine specification. Barnes found that highest efficiency was observed when injected mass was $0.311 \mathrm{~g}$ and injection duration was $23 \mathrm{CA}^{\circ}$, when simulation was running in six-stroke mode [3].

\section{Methodology of current study}

\subsection{Software selection}

In this study, AVL BOOST TM platform was selected to model a one-dimensional (1D) simulation of an engine. AVL BOOST ${ }^{\mathrm{TM}}$ is a gas-dynamic engineering software for accurate engine cycle and gas exchange simulation. The software has been widely used in industry for modelling simulation of different type of engines, including two-stroke, four-stroke, and rotary engines. Engine components (e.g. cylinder, air cleaner, and catalyst) can be used as inputs for this software. As a result, the software provides the output data of engine efficiency in many terms [21].

\subsection{Engine specification}

The model is based on the Robin EY28D engine from Subaru. The EY28D is a single cylinder, 
four-stroke, air-cooled, gasoline engine. Engine specifications are shown in Tab. 1. These engine specifications were used as a default setting for four-stroke and six-stroke models.

Tab. 1. 4-stroke engine specifications [18]

\begin{tabular}{|l|c|}
\hline Model (Subaru Robin) & EY28D \\
\hline Bore $(\mathrm{mm})$ & 75 \\
\hline Stroke $(\mathrm{mm})$ & 62 \\
\hline Displacement (cc) & 273 \\
\hline Compression ratio & 6.3 \\
\hline Connecting rod (mm) & 100 \\
\hline Piston pin offset (mm) & 0 \\
\hline A/F ratio & 14 \\
\hline Valve lift $(\mathrm{mm})$ & 10 \\
\hline Intake valve opens $\left(\mathrm{CA}^{\circ}\right)$ & 345 \\
\hline Intake valve closes $\left(\mathrm{CA}^{\circ}\right)$ & 575 \\
\hline Exhaust valve opens $\left(\mathrm{CA}^{\circ}\right)$ & 150 \\
\hline Exhaust valve closes $\left(\mathrm{CA}^{\circ}\right)$ & 370 \\
\hline Ignition point $\left({ }^{\circ} \mathrm{CA}\right.$ before $\left.\mathrm{TDC}\right)$ & 23 \\
\hline Combustion duration $\left(\mathrm{CA}^{\circ}\right)$ & 41 \\
\hline
\end{tabular}

\subsection{Engine simulation}

\subsubsection{Modelling of a four-stroke engine}

A 1D model of the Robin EY28D engine was built in AVL BOOST ${ }^{\mathrm{TM}}$ with engine specifications as given in Tab. 1. A representation of the 1D model of a four-stroke engine is illustrated in Fig. 2. Simulations were set to run with various engine speeds from 500 to $5000 \mathrm{rpm}$ although the recommended engine speed for this engine is between 2500 and $4000 \mathrm{rpm}$ [18]. To study the predicted engine performance, it is important to run the simulation beyond the range of recommended engine speeds, because in reality the engine is running with various speeds, not only in the recommended range. Results of the engine performance were collected for further analysis.

\subsubsection{Validation of four-stroke engine model}

The four-stroke engine model is validated with the performance curve of the EY28D as shown in Appendix B. Fig. 3 shows the comparison between the power curve of the real engine and the engine model.

\subsubsection{Modelling of six-stroke engine}

In order to compare results with a six-stroke engine, a second 1D model was built by using as a base the four-stroke engine model (Fig. 2). A six-stroke engine model had exactly the same components as the four-stroke engine model. However, some of the settings data was modified, since AVL BOOST ${ }^{\mathrm{TM}}$ did not support a six-stroke engine simulation. Therefore, the simulation had to be based on a four-stroke engine simulation feature. The four-stroke engine simulation feature provided only $720^{\circ} \mathrm{CA}$ for the cycle, while the six-stroke engine required $1080^{\circ} \mathrm{CA}$ for one completed cycle [17]. Thus, it was compulsory to make the six-stroke engine simulation operate within $720^{\circ} \mathrm{CA}$. For this reason, the ${ }^{\circ} \mathrm{CA}$ of each stroke of the six-stroke engine simulation was decreased to $120^{\circ} \mathrm{CA}$. In other words, a piston motion of the six-stroke engine simulation was $120^{\circ} \mathrm{CA}$ for each stroke. Furthermore, the valve timing, combustion duration and speed engine 
in the six-stroke simulation were modified, according to the new ${ }^{\circ} \mathrm{CA}$ by using Eq. (1) and Eq. (2), respectively [3].

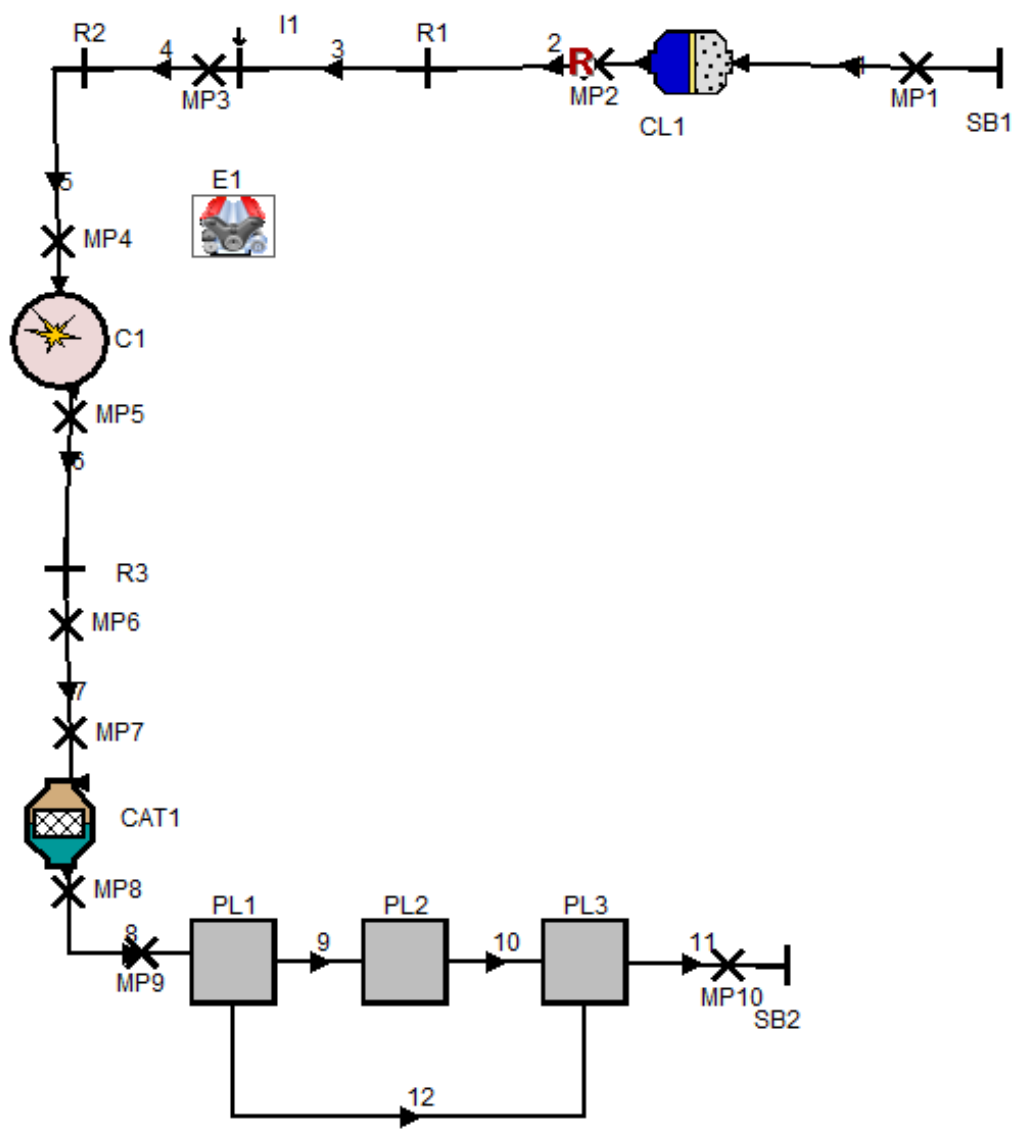

Fig. 2. Representation of the 1D AVL BOOST ${ }^{\mathrm{TM}}$ model of the four-stroke engine

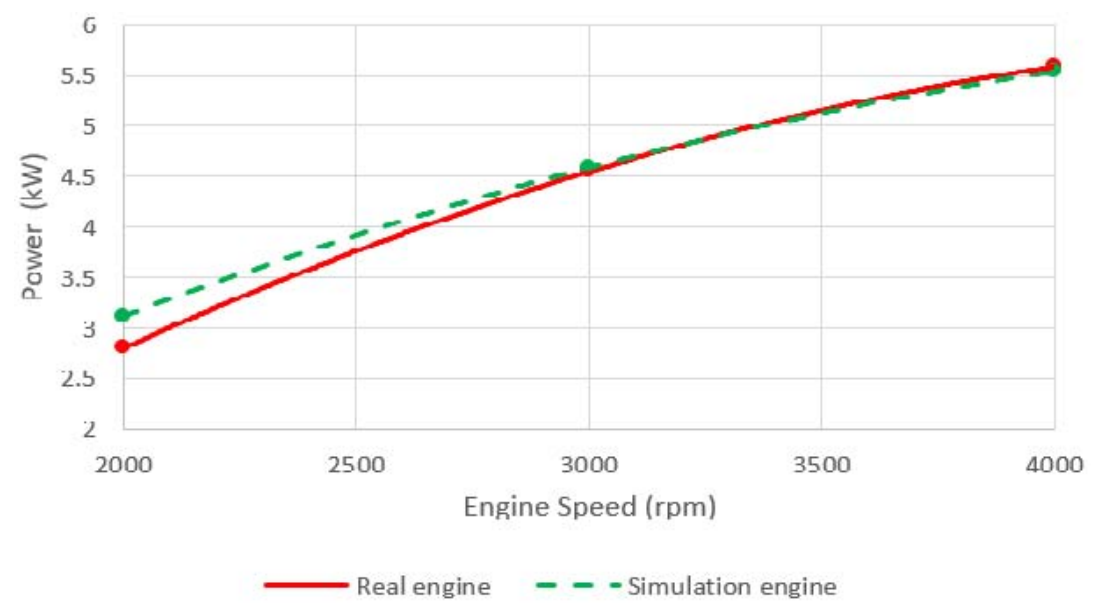

Fig. 3. Power comparison between real 4-stroke engine and model engine

$$
\begin{gathered}
\text { Osix-stroke }=(120 / 180) * \text { Aactual }, \\
R P M_{\text {six }} \text {-stroke }=(120 / 180) * \text { RPMfour-stroke. } .
\end{gathered}
$$

After the piston motion, the valve timing and engine speed were modified. At this point, the simulation performed in a six-stroke mode. However, there was no water injection option in the original 4-stroke simulation. In order to complete the six-stroke with water injection simulation, certain parameters were applied to the simulation control as shown in Fig. 4. 


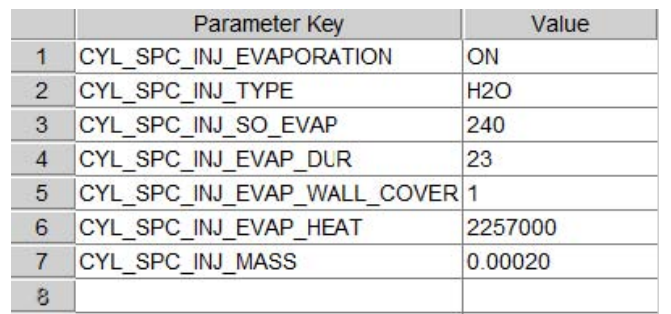

Fig. 4. Parameters for water injection simulation

One of the aims of this study was to find the most efficient camshaft for a six-stroke engine, by changing valve lift, and valve duration of the first exhaust stroke. To find the most efficient camshaft, the simulation was run with different valve lifting and valve duration. The valve lifting was varied from $5 \mathrm{~mm}$ to $10 \mathrm{~mm}$. At the same time, the valve duration was set to open longer for $2^{\circ} \mathrm{CA}$ in every new simulation by starting from valve duration of $20^{\circ} \mathrm{CA}$. However, some of the engine parameters were kept constant in these simulations, including engine speed, injection duration, injection timing, and injection mass. The simulations were running with engine speed of $4000 \mathrm{rpm}$, which is the speed of maximum power in this EY28D [18]. Besides, the injection duration used in the simulation is $23^{\circ} \mathrm{CA}$. According to [3], it was claimed that the injection duration of $23^{\circ} \mathrm{CA}$ provided the highest efficiency. The TDC was used as an injection timing in the simulations. Finally, injection mass was $0.2 \mathrm{~g}$. The effective efficiency of the combination of different valve durations and valve lift from the simulations were recorded for further analysis.

After the most suitable valve timing profile was found from the simulation, the six-stroke model was re-modelled with a new valve timing.

Next, to investigate the effect of water injection parameters on the efficiency of engine, the six-stroke engine simulation was performed with the variation of injection mass, injection timing, and engine speed. The water injected mass was varied from $0.1 \mathrm{~g}$ to $0.3 \mathrm{~g}$ with different injection timing at BTDC, TDC, and ATDC with constant injection duration. The simulations were running with engine speed between 2500 and 4000rpm, which is a recommended engine speed range for the EY28D. One injection mass was simulated with different injection timings at specific engine speed. The efficiency of different combined scenarios was collected for further analysis.

Then, a six-stroke model was updated from the earlier one with the most suitable injection point. The six-stroke model was now simulated with most efficient valve timing profile and injection parameters.

Next, the six-stroke engine model was run with engine speeds of 500-5000 rpm. Results of the engine performances and exhaust emissions were collected of further analysis.

\subsection{Design of a new camshaft}

Before designing, a result of the most efficient valve duration must be converted back into a stroke of $180^{\circ}$ by using Equation 1. Moreover, in a six-stroke engine the camshaft rotates at one-third speed of the crankshaft, since the crankshaft rotates $1080^{\circ}$ while the camshaft rotates $360{ }^{\circ} \mathrm{CA}$ in one completed cycle [9]. A unit of the valve duration was expressed in ${ }^{\circ} \mathrm{CA}$. In order to design a camshaft, the value of valve duration was multiplied by one-third. After all, of the values for designing were obtained, the SOLIDWORKS ${ }^{\mathrm{TM}}$ platform was used to design a new camshaft for the six-stroke engine.

\section{Results and Discussion}

\subsection{Power curve of Six-Stroke Engine}

Figure 5 illustrates the power graph of the validated four-stroke engine model and six-stroke 
engine model. The result shows that power is increased in the six-stroke model; this is due to the second power stroke, when water is injected in six-stroke engine. The power in six-stroke is increased by approximately $33.1 \%$.

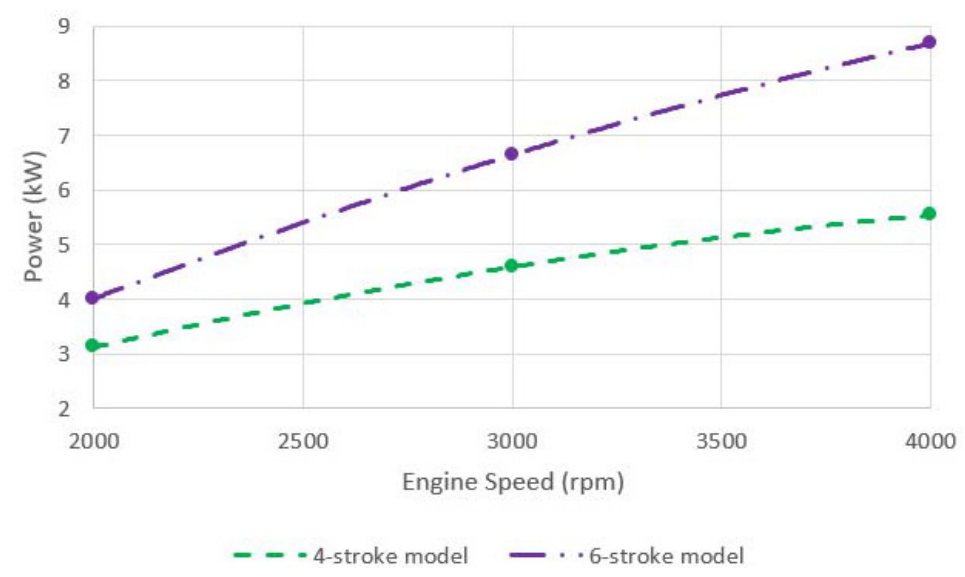

Fig. 5. Power comparison between four-stroke and six-stroke model

\subsection{The effect of first exhaust valve profile on engine efficiency}

Figure 6 shows the effect of first (during the fourth stroke) exhaust valve duration and valve lift of a six-stroke engine on the engine effective efficiency. The result shows that the effective efficiency is increased with the first exhaust valve duration. When the first exhaust valve duration is longer, there is less amount of exhaust gas trap inside the cylinder, which causes low in-cylinder pressure. As a result, less work needs to be done to push a piston upward. In contrast, when valve duration is shorter, the piston needs to do more work to move upward, due to high in-cylinder pressure. Therefore, it is possible to say that the effective efficiency increases with the decrease of in-cylinder pressure. However, beyond a specific point, effective efficiency decreases as the valve duration increases. The reason is when the valve open duration increases, the in-cylinder pressure decreases resulting in decreasing exhaust gas temperature. The hot exhaust gas helps to vaporize the injected water, which directly influences the effective efficiency of the engine. In fact, effective efficiency is decreased with steam temperature [13]. Therefore, when, the exhaust gas temperature decreases, the steam temperature decreases, and thus the effective efficiency decreases. The overall effect results in showing the maximum effective efficiency at some intermediate valve duration. In this study, the maximum effective efficiency occurs when the first exhaust valve duration is $60^{\circ} \mathrm{CA}$.

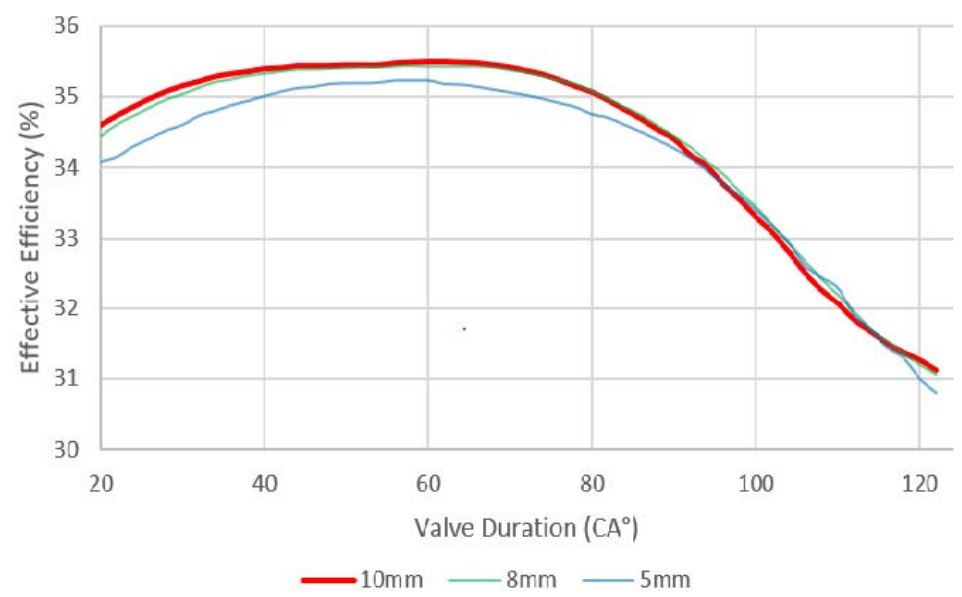

Fig. 6. Effect of first exhaust valve profile (open duration and maximum lift in the fourth stroke) on engine efficiency 
From the valve lift comparison in Fig. 6, the result shows that there is no significant difference between each valve lift of 10 and $8 \mathrm{~mm}$. However, the expected efficiency is lower when lift is $5 \mathrm{~mm}$.

The most efficient valve timing and lift profile can be investigated by combining valve lifting and valve open duration. A combination that gives the highest efficiency of $35.44 \%$ occurs when the valve open duration is $60^{\circ} \mathrm{CA}$ and valve lift is $10 \mathrm{~mm}$.

\subsection{The effect of water injection parameters on engine efficiency}

Figure 7 illustrates the effects of water injection mass and injection timing on the predicted effective efficiency at different engine speeds. The yellow dash line shows the result from a four-stroke engine.
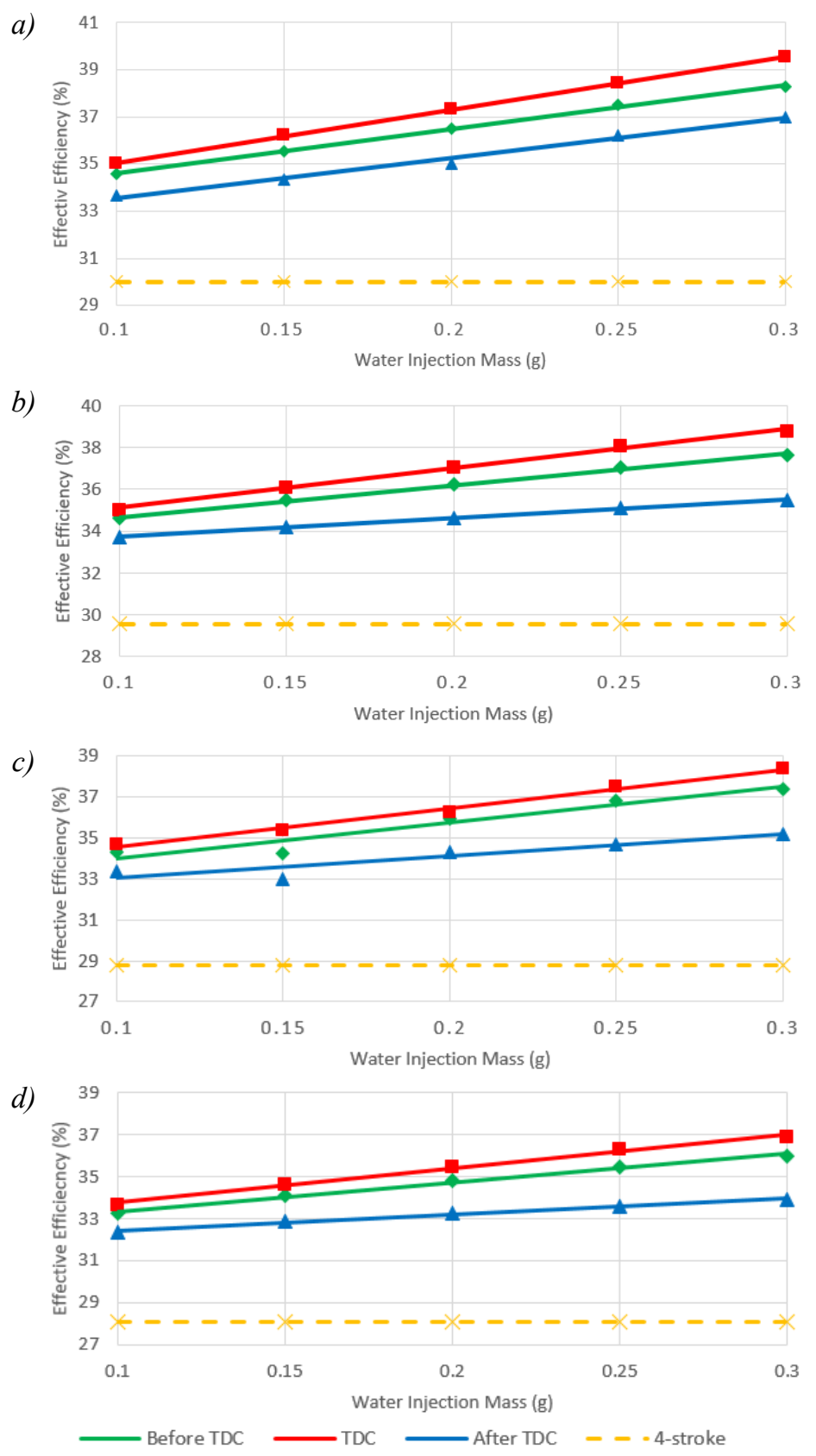

Fig. 7. The effect of water injection parameters on engine efficiency at different engine speeds: a) $2500 \mathrm{rpm}$, b) $3000 \mathrm{rpm}$, c) $3500 \mathrm{rpm}$, d) $4000 \mathrm{rpm}$ 
The results show that the effective efficiency increases with water injection mass. The reason is that more water is converted into vapour. As a result, the vapour gives the engine more power during the second power stroke. The highest efficiency was obtained when the injection mass is $0.3 \mathrm{~g}$.

Simulation was becoming unstable and a failure started to show when the mass of water injection increased above $0.3 \mathrm{~g}$. Therefore, the decision was made to leave the maximum injected mass of $0.3 \mathrm{~g}$. However, it is possible that the effective efficiency can increase further with a greater amount of injected water.

Moreover, the water injection point has a significant effect on the effective efficiency. The result in Fig. 6 shows that TDC is the most efficient injection timing, when compared to BTDC and ATDC. The reason is that when water is injected at BTDC, much of the injected water is vaporised and expands while the piston still moving upward. Due to this, work must be done to compress the expanding steam, which eventually causes loss in power and so decreases the effective efficiency. Whereas, when water is injected ATDC, the piston is already moving down. Therefore, at the point of maximum pressure, the piston is already moving too far down. Moreover, the steam may not be expanded through the full range. As a result, less power is produced.

\subsection{The comparison between four-stroke and six-stroke engine performances}

Figure 8 shows the comparison between four-stroke and six-stroke engine performance. The brake specific fuel consumption (BSFC) in a six-stroke engine is much lower than the four-stroke engine. This is because when water is injected in the six-stroke engine, the exhaust waste heat energy is converted into power for second power stroke. Due to this, BSFC is decreased by approximately $16 \%$, since more power is produced with the same amount of fuel. The lowest BSFC can be obtained in the six-stroke engine at engine speed of $3000 \mathrm{rpm}$. However, the BSFC is increased at higher engine speed, because of the increase in fiction. Similarly, BSFC is also increased at lower engine speed, since at low engine speed there is enough time for heat to transfer to the cylinder wall [11].

a)

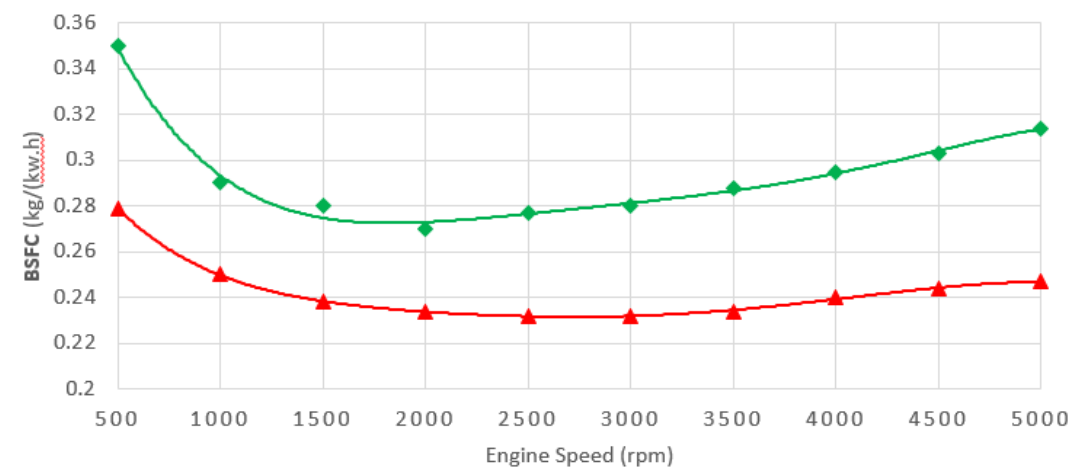

b)

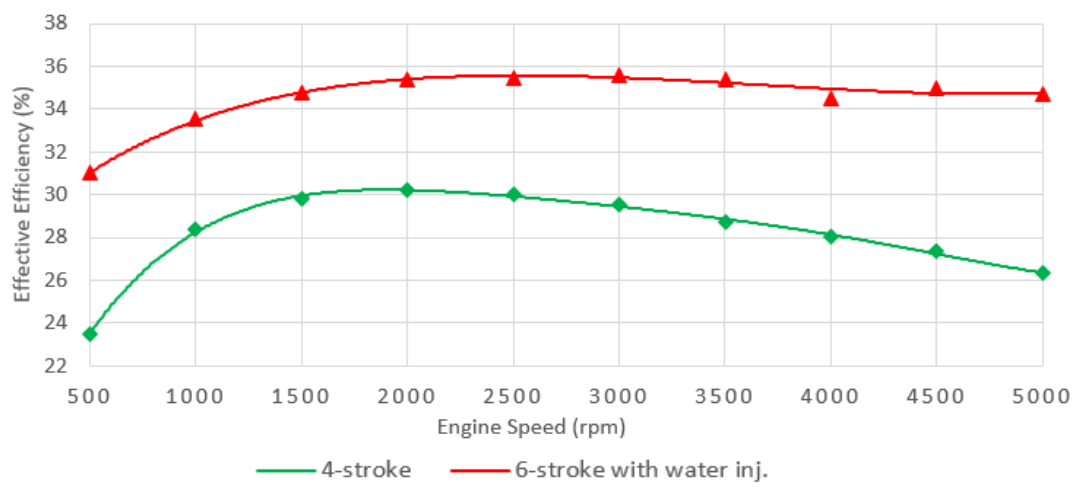

Fig. 8. Engine performances of four-stroke and six-stroke engine: a) BSFC, b) effective efficiency 
In fact, BSFC is a parameter that can be used to analyse the engine efficiency [19]. The efficiency is increased with decrease of BSFC. Therefore, the maximum efficiency can be observed at the engine speed of lowest BSFC. In this case, $3000 \mathrm{rpm}$ is the engine speed where highest efficiency is occurred.

\subsection{Exhaust emissions comparison}

The graphs of predicted Nitrogen Oxide (NOx) emissions from four-stroke and six-stroke engine are shown in Fig. 9.

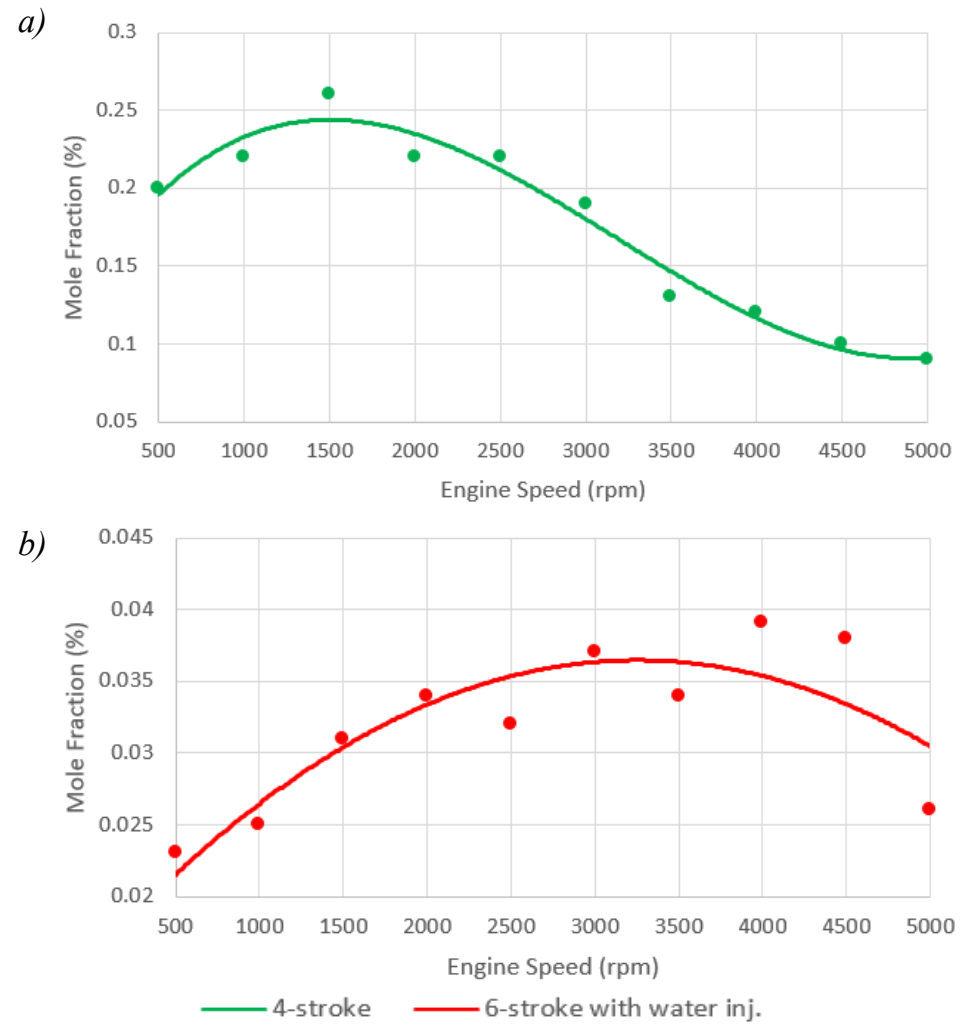

Fig. 9. NOx emissions, mole fraction: a) four-stroke engine, b) six-stroke engine

The result shows that NOx emission is reduced in the six-stroke engine. This is due to a decrease of in-cylinder temperature at the end of combustion. In fact, NOx emission increases with maximum in-cylinder temperature and pressure [2]. Thus, Injection of water in the six-stroke engine helps to reduce in-cylinder temperature, which helps to prevent formation of NOx. Due to this, the NOx emissions decrease by approximately $80 \%$ with six-stroke engine compared to the four-stroke engine case. In fact, the NOx emissions can be reduced by up to $95 \%$ depending on the amount of water and equivalence ratio [10].

Figure 10 illustrates the predicted Hydrocarbon (HC) emissions from four-stroke and six-stroke engine. Due to the decrease of in-cylinder temperature in the six-stroke engine, the HC emission is increased by approximately $85 \%$. In the six-stroke engine, incomplete combustion of HC appears when the flame approaches the cooler cylinder surface. As a result, a greater amount of unburned $\mathrm{HC}$ is emitted during the exhaust stroke [22]. In other words, the $\mathrm{HC}$ emission increases with the decrease of in-cylinder temperature.

The relationship between NOx and $\mathrm{HC}$ emission and engine speed mainly depends on two main factors, including time available for heat loss and combustion duration. As the engine speed increases, there is less time for heat loss. Therefore, the heat loss decreases, as a result, the combustion temperature increases. However, at high engine speed, combustion duration decreases resulting in decreased combustion temperature [1]. As a result of this effect, the maximum NOx 
emission occurs at some intermediate engine speed. In contrast, at the same engine speed, the minimum $\mathrm{HC}$ emission can be observed.

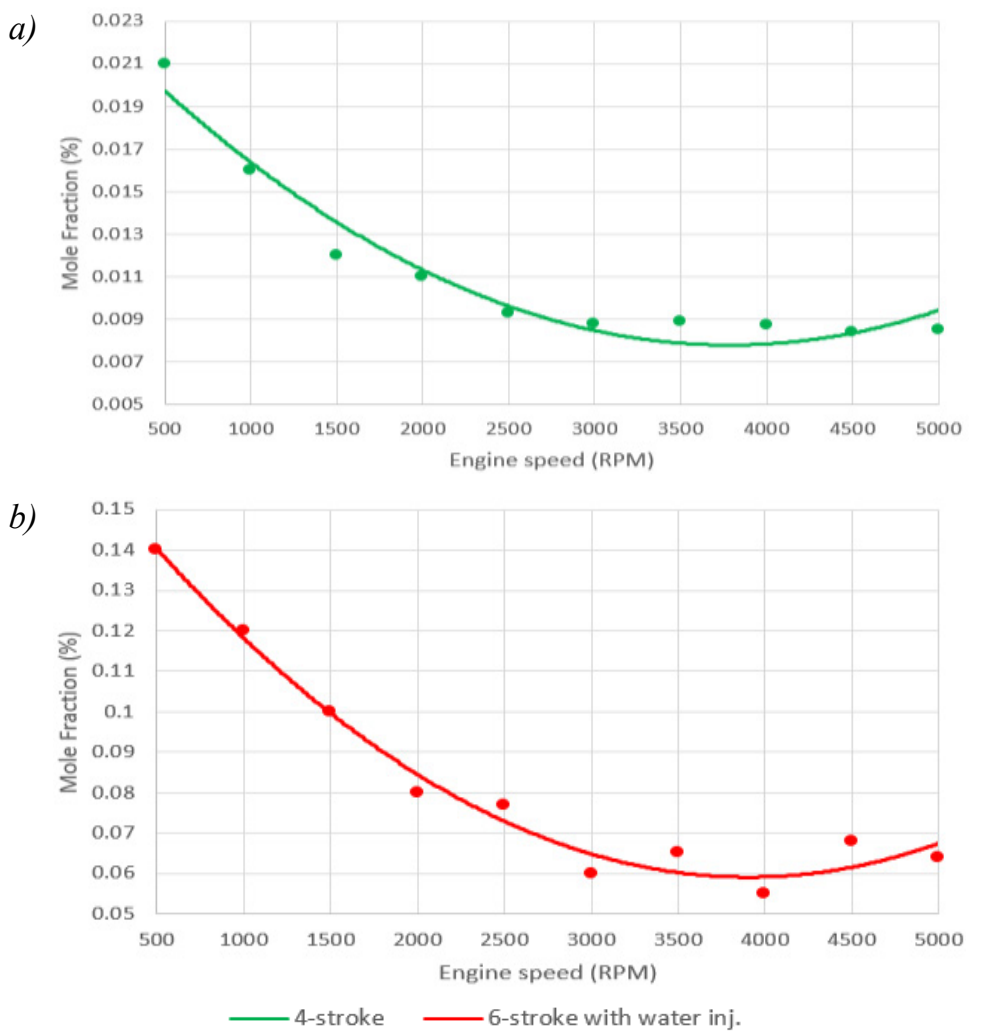

Fig. 10. HC emission mole fraction: a) four-stroke engine, b) six-stroke engine

\subsection{New camshaft design}

In order to make the six-stroke engine as efficient as possible, the result of the most efficient valve profile is used to design a camshaft for six-stroke engine. The new camshaft profile is shown in Appendix C. The first exhaust period in the new camshaft requires a high lift with short duration. This could be a problem with low engine speed, since high acceleration is required to achieve a high lift with short duration; a special tappet activation mechanism could be used between the camshaft and the valve tappet [16].

\section{Conclusion}

In this study, a 1D model of four-stroke Robin EY28D engine was built in AVL BOOST ${ }^{\mathrm{TM}}$ and converted to a model of six-stroke engine with water injection. The aims of this study were to investigate the most efficient camshaft for the six-stroke engine and engine performance when the proposed new camshaft was applied.

The effect of exhaust valve duration and valve lifting for the first exhaust on engine effective efficiency was studied to analyse for the most efficient valve profile. The result showed that the valve duration for the first exhaust has a significant effect on the effective efficiency, due to its effect on in-cylinder pressure and temperature. Meanwhile, the valve lift has only slight effect on the effective efficiency. When valve duration is $60^{\circ} \mathrm{CA}$ and valve lift is $10 \mathrm{~mm}$, the highest effective efficiency is observed, with a value of $35.44 \%$. This valve profile is then used to re-model the engine for the six-stroke mode of operation and to simulate for engine performance.

The results from the simulations showed that the six-stroke engine is more efficient than four-stroke engine. In six-stroke engine, an average BSFC is decreased by approximately $16 \%$, 
due to conversion of exhaust heat into useful power in second power stroke that allows the six-stroke engine to produce more power with the same amount of fuel. In addition, more power is produced with higher amount of injected water. It can be said that the engine efficiency increases with the mass of injected water. In this study, highest efficiency occurs when $0.3 \mathrm{~g}$ of water is injected at TDC. Moreover, the injected water also helps to reduce the in-cylinder temperature. Due to this, the NOx emission in six-stroke engine is decreased by approximately $80 \%$. In contrast, the $\mathrm{HC}$ emission is increased by about $85 \%$ because of cooler in-cylinder temperature.

The new camshaft for the six-stroke engine was designed according to the most efficient first exhaust valve profile of $60^{\circ} \mathrm{CA}$ and $10 \mathrm{~mm}$ lifting.

\section{Acknowledgments}

This work was partly supported by "KNOCKY" project received funding from European Union Horizon2020 research and innovation programme under the Grant agreement No. 691232. .

\section{References}

[1] Anetor, L., Osakue, E., Odetunde, C., Effect of Some Spark Ignition Engine Operating Variables on NOX Production and Control, Arabian Journal for Science and Engineering, Vol. 42 (5), pp. 2087-2103, 2017.

[2] Arabaci, E., İçingür, Y., Solmaz, H., Uyumaz, A., Yilmaz, E., Experimental investigation of the effects of direct water injection parameters on engine performance in a six-stroke engine, Energy Conversion and Management, Vol. 98, pp. 89-97, 2015.

[3] Barnes, P., Six-stroke engine with water injection simulation, BEng Project, University of Birmingham, School of Engineering, 2018.

[4] Conklin, J., Szybist, J., A highly efficient six-stroke internal combustion engine cycle with water injection for in-cylinder exhaust heat recovery, Energy, Vol. 35 (4), pp. 1658-1664, 2010.

[5] Crumbley, K., 7 Important Uses for Crude Oil and Why It Matters [online], Bible Money Matters. Available at: https://www.biblemoneymatters.com/7-important-uses-for-crude-oiland-why-it-matters/ [Accessed 1 Mar. 2019].

[6] Dyer, L., Internal-combustion engine, 1339176, 1920.

[7] Gasim, M. M., Chui, L. G., Bin Anwar, K. A., Six Stroke Engine Arrangement, 15th International Conference on Applied Mechanics and Mechanical Engineering, 2012.

[8] Griffin, S., Method of operating gas engines, USPTO 412883, 1889.

[9] Gupta, K., Suthar, K., Jain, S., Agarwal, G., Nayyar, A., Design and experimental investigations on six-stroke SI engine using acetylene with water injection, Environmental Science and Pollution Research, Vol. 25 (23), pp. 23033-23044, 2018.

[10] Harrington, J., Water Addition to Gasoline-Effect on Combustion, Emissions, Performance, and Knock, SAE Technical Paper 820314, 1982.

[11] Heywood, J., Internal combustion engine fundamentals, 2nd ed. McGraw-Hill, 2018.

[12] Innovatemotorsports.com, Spark Timing Myths Debunked-Spark Timing Myths Explained: Application Notes [online], Available at: https://www.innovatemotorsports.com/resources/ myths.php [Accessed 5 May 2019].

[13] Isherwood, Expansion of steam in the steam-engine, Journal of the Franklin Institute, Vol. 106 (2), pp. 73-94, 1878.

[14] Kumar Tyagi, V., Study and Analysis of Six Stroke Engine, International Journal of Scientific \& Engineering Research, Vol. 6, Iss. 5, 2015.

[15] Manning, J., Internal combustion engine design. Shoreham-by-Sea: Ricardo UK, 2012.

[16] Mohamad, T., Abdul Rasid, A., Improvement of Full-Load Performance of an Automotive Engine Using Adaptive Valve Lift and Timing Mechanism, Advances in Automobile Engineering, 05(02), 2016. 
[17] Naresh, P., Concept Six Stroke Engine, Journal of Advancement in Engineering and Technology Science Q, December 18, 2015.

[18] Service manual, 1st ed. Wood dale: Robin Industrial Engines.

[19] Stark, A., Brake Specific Fuel Consumption (BSFC) [online] X-engineer.org. Available at: $\mathrm{https}$ //x-engineer.org/automotive-engineering/internal-combustion-engines/performance /brake-specific-fuel-consumption-bsfc/ [Accessed 3 Mar. 2019].

[20] Statista, Daily global crude oil demand 2006-2019 | Statistic [online], Available at: https:// www.statista.com/statistics/271823/daily-global-crude-oil-demand-since-2006/ [Accessed 26 Feb. 2019].

[21] Uk.mathworks.com, AVL BOOST [online] Available at: https://uk.mathworks.com/products/ connections/product_detail/avl-boost.html [Accessed 5 Feb. 2019].

[22] Wilson, P., Effects of Water Injection and Increased Compression Ratio in a Gasoline Spark Ignition Engine, Postgraduate, University of Idaho, 2011.

\section{Appendix A: Abbreviations}

1D - one dimensional

A/F - Ait/Fuel

ATDC - After Top Dead Centre

BSFC - Brake Specific Fuel Consumption

BTDC - Before Top Dead Centre

$\mathrm{CA}^{\circ}-$ Crank Angle

$\mathrm{CO}$ - Carbon Monoxide

$\mathrm{HC}$ - Hydrocarbon

NOx - Nitrogen Oxide

Rpm - Revolutions per Minute

TDC - Top Dead Centre

\section{Appendix B: Subaru EY28D Engine power and torque curve}

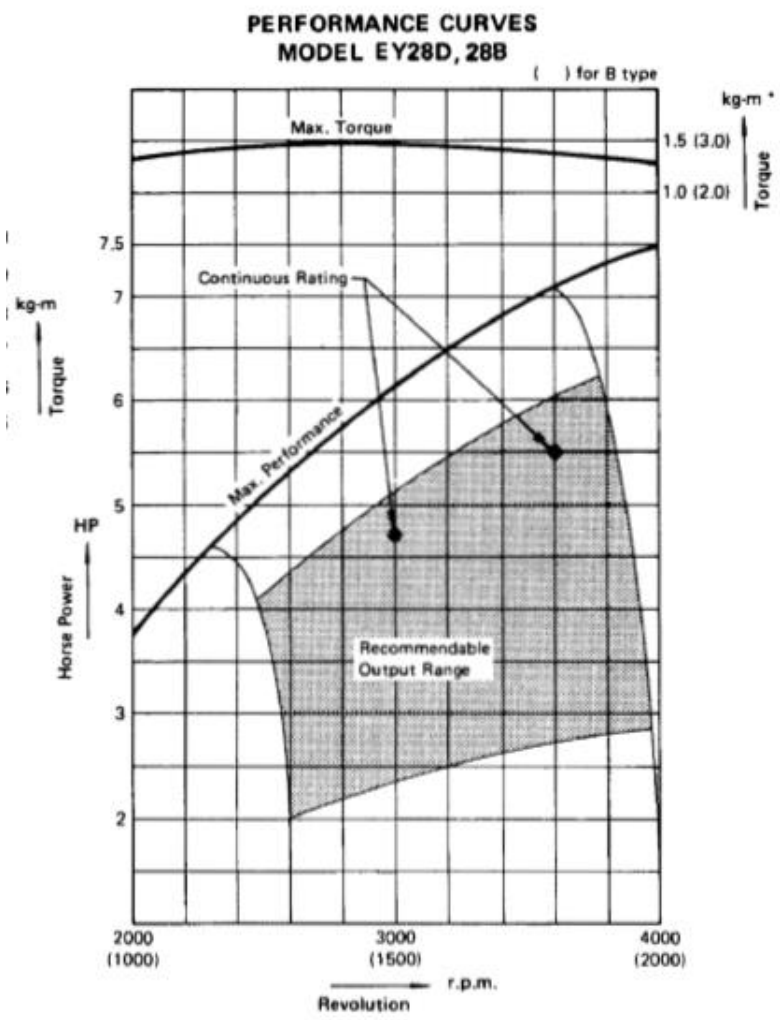




\section{Appendix C: Design of the new camshaft}
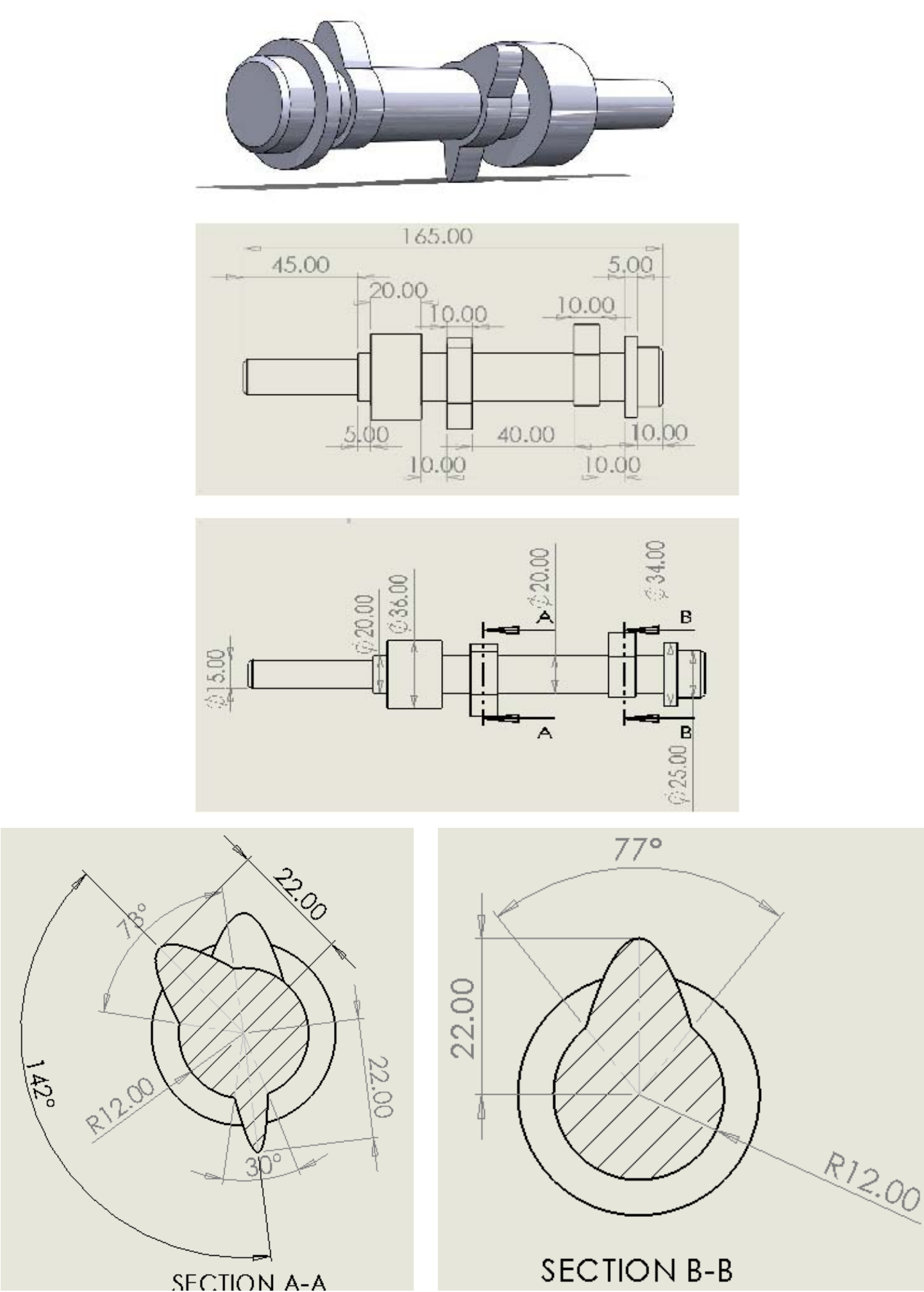

SECTION B-B

Manuscript received 26 March 2019; approved for printing 27 June 2019 